EDITOR'S CHOICE

\title{
Unintentional injuries among children in resource poor settings: where do the fingers point?
}

\author{
Bhuvaneswari Balan, Lakshmi Lingam
}

\begin{abstract}
- Additional appendices are published online only. To view these files please visit the journal online (http://adc.bmj.com/ content $/ 97 / 1$.toc)
\end{abstract}

School of Social Sciences, Tata Institute of Social Sciences, Mumbai, India

\section{Correspondence to}

Bhuvaneswari Balan, $\mathrm{PhD}$ Research Scholar, School of Social Sciences,

Tata Institute of Social Sciences, Mumbai, India; bhuvaneswarisharma@ gmail.com

Accepted 18 August 2011 Published Online First 26 September 2011

\begin{abstract}
Every year, over 875000 children between 0 and 18 years of age die as a result of unintentional injuries (UIs), with a higher proportion occurring in low- and middleincome countries (LMICs): the WHO 2008 World Report on Child Injury Prevention shows a child UI death rate 3.4 times greater in LMICs than in high income countries (HICs) (41.7 per million vs 12.2 per million, respectively). Deaths due to injuries from drowning, burns and falls are significantly higher among LMICs at 7.8, 4.3 and 2.1 per million, respectively, as compared to HICs with $1.2,0.4$ and 0.4 per million, respectively. The authors present a review of childhood Uls in LMICs undertaken to determine demographic and socioeconomic risk factors. As in industrialised settings, age, gender and social deprivation are significant factors in determining Ul-related vulnerability among children. However, certain patterns are unique to LMICs, including road traffic injuries among child pedestrians, drowning and accidental paraffin poisoning. These demand contextual understanding and the implementation of appropriate injury control measures, which are currently inadequate.
\end{abstract}

\section{INTRODUCTION}

Unintentional injuries (UIs) among children are a major and largely preventable cause of death and disability in low and middle income countries (LMICs) with preventive legislation hopelessly inadequate to protect this vulnerable population. Existing studies indicate that UI rates are significantly higher in LMICs compared to high income countries (HICs). ${ }^{1-3}$ Figure 1 shows the disproportionate burden of UIs on children in LMICs. With the high injury rates and poor identification of injuries as risk factors, the situation could be likened to human rights abuse.

Children are more vulnerable to UIs due to their curiosity to experiment and explore their surroundings coupled with an inability to understand or perceive danger. ${ }^{3}$ Children are also at risk of worse injury due to their smaller size and physiological immaturity. In addition, the burden of injury is greater among children since they have more years ahead of them to be affected by disability. ${ }^{3}$

Despite higher rates of injury-related mortality among children, there is little policy focus on the subject in LMICs. The lack of recognition of the magnitude of the problem is reflected in the poor availability and monitoring of data, and the dearth of effective prevention strategies to reduce injury mortality.

This paper attempts to: (1) undertake a review of the literature on UIs among children in LMICs; (2) explore the various associated socio-cultural and demographic factors; and (3) explore contextspecific patterns in injuries and injury prevention.

\section{METHODOLOGY}

A literature review was undertaken of original research articles on UIs among children $<18$ years of age in LMICs. Keywords used in the search were unintentional injuries (including specific terms such as burns, drowning, poisoning), children, accidents, injuries, and middle- and lowincome countries. UIs, the focus of this paper, include falls, burns, drowning, road traffic injuries (RTIs) and unintentional poisoning. ${ }^{5}$ Intentional injuries such as suicide, violence and abuse, and injuries as a result of war were excluded. Injuries to special populations (for instance, among differently-abled children) were also excluded. Studies carried out and published between 1990 and 2011 were considered. The search for web-based articles was conducted using Google Scholar and other search engines, digital archives and e-resources such as ISTOR, Oxford Journals, The Lancet, Sage Journals Online and BMJ Journals. Only full-text articles in English that described UIs among children according to the inclusion criteria were reviewed.

The search identified 64 full text articles on injuries. However, 35 articles were excluded since they considered HICs or did not focus on children. The remaining 29 (25 original studies and four reviews) full text articles in English on injuries among children in LMICs were included in the study and categorised as follows:

- Facility/hospital-based studies - 14

- Community-based studies -5

- Review (including systematic reviews) articles -4

- Studies on socioeconomic factors and child UIs -3

- Parental perception and home environment in relation to child UIs -3 .

Of the 29 articles reviewed, 16 were from South Asia, seven from Africa, two from the Western Pacific Region, one from the eastern Mediterranean region, and the remaining three addressed developing countries (LMICs) in general.

\section{EPIDEMIOLOGY}

A number of predictable social, demographic and economic factors in LMICs are associated with vulnerability to UIs in childhood. For instance, age, gender and socioeconomic status are significant factors related to UI vulnerability. The WHO and UNICEF data given in table 1 reveal the higher UI mortality in LMICs and show that boys are more vulnerable to most forms of UIs in all age groups. There are two exceptions: girls are more 
vulnerable to fire-related injuries in all age groups and girl children below the age of 1 seem to be at greater risk than boys for all UIs (discussed below). Fourteen of the 25 original studies reviewed for this paper (listed in the online supplementary appendices) show a greater male susceptibility to injury; the highest number of injuries occur in the home and children are mostly injured while at play or taking part in leisure activities. Falls were the most common form of injury occurring in the home due to poor safety measures. ${ }^{67}$

\section{SUMMARY OF FINDINGS \\ Gender}

Most of the studies reviewed here show a higher injury prevalence among male children. Explanations for this include the fact that male children take more risks and are more impulsive than girls. Also, culturally, boys are given relatively greater freedom to explore their environment. ${ }^{1}$ Interestingly however, girl children in LMICs have a higher prevalence of fire-related injuries (table 1). ${ }^{3} 89$ The genderbased roles that girls play from an early age involve exposure to cooking in open and unsafe kitchens ${ }^{1}$ and attending to younger siblings while mothers cook, which could contribute to this pattern. Use of clothing with a higher risk of firerelated accidents may also predispose to burns rather than other forms of injury. ${ }^{3}$ Furthermore, the higher prevalence of all forms of UI mortality among girl children below the age of 1 is a disturbing factor. A study by Giashuddin et al in Bangladesh throws light on the vulnerability of the female child to mortality following injury compared to boys due to the preferential treatment towards boys in seeking medical attention. ${ }^{10}$ In countries like India where domestic violencerelated burns and deaths among women and young girls are common, the intent of injury is crucial. Thus, a gender-based understanding of child UIs in LMICs is critical for the exploration of cultural factors that might frustrate injury control measures. The problem is further complicated by poor protocols for death registration.

\section{Age}

Injury patterns are age related. Younger children are more vulnerable to injuries in the home such as poisoning (from household agents like paraffin/kerosene), burns and falls, while older children show greater vulnerability to RTIs while walking or cycling. ${ }^{11-15}$ Children above the age of 5 are highly vulnerable to all forms of UI ${ }^{1617}$ due to their level of mobility, increased exposure to the environment and decreased level of supervision, although

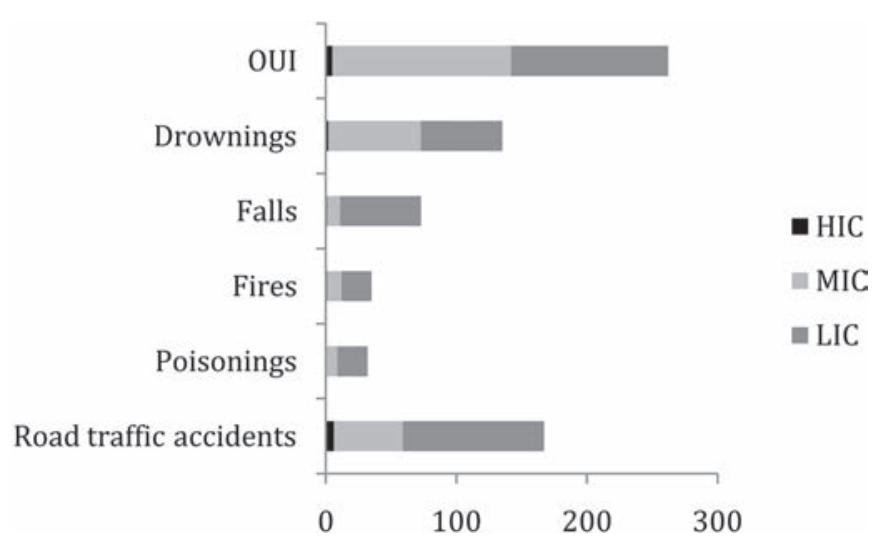

Figure 1 Unintentional injury mortality for 0-14-year-old children (in thousands) by income group. HIC, high-income countries; LIC, low-income countries; MIC, middle-income countries; OUI, other unintentional injuries.

Source: The Global Burden of Disease, 2004 Update

Table 1 Estimated mortality level of the world by sex, age and income level per 100000,2004

\begin{tabular}{|c|c|c|c|c|c|c|c|c|c|c|c|c|c|c|c|c|}
\hline \multirow[b]{2}{*}{ Injury types } & \multirow{2}{*}{$\begin{array}{l}\text { Income } \\
\text { level }\end{array}$} & \multicolumn{3}{|c|}{$<1$ Years } & \multicolumn{3}{|c|}{ 1-4 Years } & \multicolumn{3}{|c|}{ 5-9 Years } & \multicolumn{3}{|c|}{ 10-14 Years } & \multicolumn{3}{|c|}{ 15-19 Years } \\
\hline & & Boys & Girls & All & Boys & Girls & All & Boys & Girls & All & Boys & Girls & All & Boys & Girls & All \\
\hline \multirow[t]{3}{*}{ All unintentionalinjuries } & LMIC & 99.7 & 106.4 & 102.9 & 51.0 & 48.2 & 49.7 & 41.4 & 33.4 & 37.6 & 30.0 & 21.3 & 25.8 & 53.3 & 31.2 & 42.6 \\
\hline & $\mathrm{HIC}$ & 39.2 & 16.3 & 28.0 & 10.0 & 6.9 & 8.5 & 6.9 & 4.3 & 5.6 & 7.9 & 4.3 & 6.1 & 34.6 & 12.7 & 23.9 \\
\hline & All & 94.3 & 98.1 & 96.1 & 47.2 & 44.3 & 45.8 & 38.1 & 30.6 & 34.4 & 27.8 & 19.6 & 23.8 & 51.4 & 29.3 & 40.6 \\
\hline \multirow[t]{3}{*}{ Road trafficinjuries } & LMIC & 11.1 & 7.8 & 9.5 & 10.4 & 8.9 & 9.7 & 14.3 & 10.1 & 12.3 & 9.2 & 4.7 & 7.0 & 23.3 & 7.6 & 15.7 \\
\hline & $\mathrm{HIC}$ & 15.6 & 2.7 & 9.3 & 2.7 & 2.5 & 2.6 & 3.0 & 2.3 & 2.6 & 4.1 & 2.5 & 3.3 & 24.5 & 10.3 & 17.6 \\
\hline & All & 11.5 & 7.4 & 9.5 & 9.7 & 8.3 & 9.0 & 13.3 & 9.3 & 11.4 & 8.7 & 4.5 & 6.6 & 23.4 & 7.9 & 15.9 \\
\hline \multirow[t]{3}{*}{ Falls } & LMIC & 7.2 & 4.0 & 5.7 & 2.3 & 2.1 & 2.2 & 2.4 & 1.9 & 2.2 & 1.3 & 0.8 & 1.0 & 2.8 & 1.6 & 2.2 \\
\hline & HIC & 2.4 & 0.6 & 1.5 & 0.5 & 0.2 & 0.4 & 0.3 & 0.1 & 0.2 & 0.2 & 0.1 & 0.2 & 1.0 & 0.2 & 0.6 \\
\hline & All & 6.8 & 3.7 & 5.3 & 2.1 & 1.9 & 2.0 & 2.2 & 1.8 & 2.0 & 1.2 & 0.7 & 1.0 & 2.6 & 1.5 & 2.1 \\
\hline \multirow[t]{3}{*}{ Drowns } & LMIC & 6.7 & 10.6 & 8.6 & 12.7 & 8.2 & 10.6 & 8.5 & 5.4 & 7.0 & 9.1 & 4.4 & 6.8 & 10.0 & 4.2 & 7.2 \\
\hline & HIC & 2.0 & 0.9 & 1.5 & 2.8 & 1.3 & 2.1 & 1.2 & 0.4 & 0.9 & 1.0 & 0.3 & 0.6 & 2.7 & 0.3 & 1.5 \\
\hline & All & 6.4 & 9.8 & 8.0 & 11.8 & 7.6 & 9.8 & 7.8 & 4.9 & 6.4 & 8.3 & 4.0 & 6.2 & 9.3 & 3.8 & 6.6 \\
\hline \multirow[t]{3}{*}{ Fire-relatedinjuries } & LMIC & 9.1 & 13.2 & 11.1 & 6.6 & 8.4 & 7.5 & 2.7 & 2.9 & 2.8 & 1.4 & 2.6 & 2.0 & 1.8 & 6.6 & 4.1 \\
\hline & HIC & 0.8 & 0.4 & 0.6 & 0.8 & 0.7 & 0.8 & 0.5 & 0.4 & 0.5 & 0.3 & 0.3 & 0.3 & 0.3 & 0.2 & 0.2 \\
\hline & All & 8.4 & 12.0 & 10.1 & 6.1 & 7.6 & 6.8 & 2.5 & 2.7 & 2.6 & 1.3 & 2.4 & 1.8 & 1.6 & 6.0 & 3.7 \\
\hline \multirow[t]{3}{*}{ Poisoning } & LMIC & 5.8 & 4.1 & 5.0 & 3.2 & 2.2 & 2.7 & 1.4 & 1.3 & 1.4 & 1.3 & 1.4 & 1.3 & 2.1 & 2.1 & 2.1 \\
\hline & HIC & 1.4 & 0.2 & 0.8 & 0.1 & 0.1 & 0.1 & 0.1 & 0.0 & 0.0 & 0.1 & 0.1 & 0.1 & 2.0 & 0.7 & 1.4 \\
\hline & All & 5.4 & 3.7 & 4.6 & 2.9 & 2.0 & 2.5 & 1.3 & 1.2 & 1.2 & 1.1 & 1.2 & 1.2 & 2.1 & 2.0 & 2.0 \\
\hline \multirow[t]{3}{*}{ Other unintentionalinjuries } & LMIC & 59.7 & 66.9 & 63.1 & 15.7 & 18.5 & 17.1 & 12.1 & 11.8 & 12.0 & 7.9 & 7.5 & 7.7 & 13.4 & 9.1 & 11.3 \\
\hline & HIC & 17.0 & 11.7 & 14.4 & 3.1 & 2.0 & 2.6 & 1.9 & 1.0 & 1.4 & 2.2 & 1.0 & 1.6 & 4.2 & 1.0 & 2.6 \\
\hline & All & 55.9 & 61.6 & 58.7 & 14.5 & 16.9 & 15.7 & 11.1 & 10.7 & 10.9 & 7.3 & 6.8 & 7.1 & 12.4 & 8.2 & 10.4 \\
\hline
\end{tabular}

Source: World report on child injury prevention, WHO \& UNICEF, 2008.

Other injuries include smothering, asphyxiation, choking, animal or snakebites, hypothermia and hyperthermia as well as natural disasters.

HIC, high-income countries; LMIC, low and middle income countries. 
Table 2 Specific instances of unintentional injuries in LMICs

\begin{tabular}{|c|c|c|c|c|}
\hline & Drowning in Bangladesh & $\begin{array}{l}\text { Paraffin poisoning in African } \\
\text { countries }\end{array}$ & RTIs in developing countries & Falls in India \\
\hline Special factors & $\begin{array}{l}\text { Accidental drownings in Bangladesh } \\
\text { mostly occur in natural water bodies } \\
\text { like ponds, in contrast to HICs where } \\
\text { drownings occur mostly in swim- } \\
\text { ming pools. }{ }^{11423} \\
\text { Children between } 1 \text { and } 2 \text { years of } \\
\text { age are most vulnerable to drown- } \\
\text { ing. }{ }^{11} 142324\end{array}$ & $\begin{array}{l}\text { In African countries like Kenya and } \\
\text { Malawi, and in Jordan, the majority } \\
\text { of accidental poisonings involve } \\
\text { paraffin. } \\
\text { Children below } 2 \text { years of age } \\
\text { are the most vulnerable, with the } \\
\text { majority of injuries occurring in the } \\
\text { summer. }{ }^{21} 2225\end{array}$ & $\begin{array}{l}\text { Unlike in HICs, RTIs among children } \\
\text { in developing countries mostly } \\
\text { affect pedestrians and bicyclists. } \\
\text { Children above } 5 \text { years of age } \\
\text { are more vulnerable due to their } \\
\text { greater mobility and freedom. }{ }^{112}\end{array}$ & $\begin{array}{l}\text { Falls are the most prevalent form } \\
\text { of unintentional injury in India. } 6712 \\
\text { Falls occur mostly from rooftops, } \\
\text { staircases, windows, and into } \\
\text { bore wells and manholes due to } \\
\text { poor safety measures. }\end{array}$ \\
\hline Similarities & $\begin{array}{l}\text { The majority of child drownings } \\
\text { occur while the child is at play. } \\
\text { Lack of safety measures is a major } \\
\text { concern in prevention. } \\
\text { There is a lack of information and } \\
\text { research on first aid best practice. }\end{array}$ & $\begin{array}{l}\text { Storage of household chemicals } \\
\text { in beverage bottles and within the } \\
\text { reach of children. } \\
\text { Poor knowledge of first aid } \\
\text { for paraffin poisoning where } \\
\text { inducing vomiting creates further } \\
\text { complications. }{ }^{2122}\end{array}$ & $\begin{array}{l}\text { Most RTIs occur while children are } \\
\text { at play. } \\
\text { Structural factors like households } \\
\text { opening directly into streets pose a } \\
\text { greater danger to younger children. }\end{array}$ & $\begin{array}{l}\text { Falls among children occur mostly } \\
\text { during play. } \\
\text { Main causes include poor safety } \\
\text { measures in the home like lack of } \\
\text { banisters or window panes, poor } \\
\text { or missing rooftop fencing, open } \\
\text { bore wells and manholes. }{ }^{67}\end{array}$ \\
\hline $\begin{array}{l}\text { Suggestions for injury } \\
\text { prevention/control }\end{array}$ & $\begin{array}{l}\text { Fencing of homes suggested as a } \\
\text { more feasible option than fencing off } \\
\text { water bodies. }{ }^{14} \\
\text { Further research on traditional first } \\
\text { aid practices like the spinning of a } \\
\text { drowned child to remove water (the } \\
\text { benefits and harms) is necessary to } \\
\text { develop safer first aid practices. }\end{array}$ & $\begin{array}{l}\text { Introducing child resistant cans } \\
\text { has been proven to be an effective } \\
\text { technique. } \\
\text { Safe storage of household } \\
\text { chemicals. } \\
\text { Educating caregivers on appropri- } \\
\text { ate first aid techniques. } \\
\text { Overall less reliance on kerosene } \\
\text { within the household. }^{13}\end{array}$ & $\begin{array}{l}\text { Lane separation for pedestrians } \\
\text { and motorised vehicles. } \\
\text { Developing safe play areas. }\end{array}$ & $\begin{array}{l}\text { Smoother land surfaces in the } \\
\text { home to cushion falls. }{ }^{67} \\
\text { Use of safety measures in the } \\
\text { home and on the streets. } \\
\text { Safe and separate ground level } \\
\text { play areas. }\end{array}$ \\
\hline
\end{tabular}

The unintentional injuries in LMICs listed in the table emphasise the need to include household structural and behavioural factors in any review of injury control measures. HIC, high-income countries; LMICs, low- and middle-income countries; RTI, road traffic injuries.

cognitively they have not yet developed fully. ${ }^{3467}$ Ironically, children above 5 receive less attention than those below 5 due to the greater attention given to under- 5 mortality from infectious diseases, an ongoing serious situation in LMICs. ${ }^{16}$

\section{Social class}

There is an inverse association between socioeconomic status and injury. Poorer families are more vulnerable and exposed to hazards in and outside the home, thus increasing vulnerability to injury among their children. ${ }^{6} 10121518-20$ In Bangladesh, poor children are 2.8 times more likely to die following injury. ${ }^{10}$ Some of the factors inherent to social deprivation that increase the risk of child injury include floor level cooking, poor storage of hazardous materials such as kerosene, lack of safe play areas, supervision of young children by their older siblings and lack of appropriate safety measures in and around the home. This situation also pertains in lower socioeconomic areas in developed countries such as Australia and the United Kingdom, especially for RTIs.

\section{PREVENTIVE STRATEGIES}

Acknowledging child UIs as a public health concern and spreading awareness requires contextual interventions. The traditional approach of the three Es of injury control, namely enforcement, education and engineering, needs to become context specific with multiple collaborators. Contextual understanding enables injury control measures to be prioritised.

Enforcement of legislation indicates state awareness of the importance and urgency of the problem. ${ }^{1}$ However, in LMICs laws around injuries are inadequate and seldom proactive. While some measures such as zero tolerance of driving while intoxicated entail strict penalties and imprisonment for drunk drivers, laws concerning product and infrastructure safety requirements are still at an early stage. Child-resistant containers for poisonous household substances reduce accidental poisoning but are not yet mandatory by law. ${ }^{26}$
Education is an effective tool to prevent injuries. In settings lacking skilled health care workers, in collaboration with nongovernmental organisations 'barefoot' health care workers could be trained to enhance awareness among families and conduct community-based surveys. Focussed education on specific injury measures might be more effective than general awareness. For instance, training in first aid measures for kerosene/paraffin poisoning needs to be provided (especially in African countries) to ensure that caretakers do not induce vomiting in children, which could lead to further damage. ${ }^{21} 22$

Engineering measures to prevent injuries, such as environmental and product modification, need extensive exploration in LMIC settings. Lane separation for different type of vehicles, the diversion of traffic away from residential areas, the installation of safety devices in the home, school and cars, the provision of safe play spaces, the manufacture of safe toys for children, and child-proof caps on medicine and household chemical containers are some of the injury control measures that would ensure a safer environment for children.

In addition, improved emergency trauma care and improved rehabilitation services are paramount in ensuring better recovery. Hyder et al in their study on injuries among children under 5 years of age in South Asia state that $60 \%$ of paediatric admissions are due to injuries and that hospitals are poorly equipped to deal with these patients. ${ }^{2}$ Furthermore, global surveillance of injuries leads to better comprehension and comparisons on a larger scale.

\section{WHY THE INERTIA?}

UIs have not received the requisite attention from researchers, legislators and policy makers due to:

- Lack of awareness of the severity of child UIs coupled with the poor availability of data in LMICs.

- Injuries are considered 'accidental' with the onus mainly on the victims and their caretakers, thus absolving the authorities (such as legislators and policy makers) from responsibility, which is unhelpful for tackling the issue. 
- Competing health priorities and greater focus on communicable diseases and malnutrition, especially in the $0-5$-yearold age group, have sidelined UIs.

- Poor research on injuries and lack of clarity on contributory factors further compound the inertia.

\section{DIRECTIONS FOR FUTURE RESEARCH}

Child UIs are afforded little attention in LMICs and even less legislative commitment. The present review has described some of the deficits. We feel the following topics are worthy of future research:

- Gender vulnerability to UIs needs to be scrutinised further due to the various sociocultural factors that favour male children.

- Collaborative research endeavours that explore the medical, sociocultural and spatial concerns around child UIs would help provide greater clarity.

- Contextual understanding of the factors leading to child UIs needs to be explored in parallel with developing universal surveillance systems to ensure effective injury control measures.

- The role of barefoot community health workers as key resources in educating families and conducting community surveys needs further investigation.

- Environmental and product modifications as potential effective injury control measures must be explored and implemented in LMICs.

\section{Competing interests None.}

Provenance and peer review Commissioned; internally peer reviewed.

\section{REFERENCES}

1. WHO. World Report on Child Injury Prevention: Summary. Geneva: World Health Organisation, 2008. http://whqlibdoc.who.int/ publications/2008/9789241563574 eng.pdf (accessed 17 Mar 2010).

2. Hyder AA, Wali S, Fishman S, et al. The burden of unintentional injuries among the under-five population in South Asia. Acta Paediatr 2008:97:267-75.

3. Bartlett SN. The problem of children's injuries in low-income countries: a review. Health Policy Plan 2002;17:1-13.

4. Nath A, Naik VA. Profile of Accidents in Children Less than Five years of Age belonging to a rural community in Belgaum District. Indian J Community Med 2007;32:133-4.

5. Krug EG, Sharma GK, Lozano R. The global burden of injuries. Am J Public Health. 2000;90:523-6.
6. Tandon JN, Kalra A, Kalra K, et al. Profile of accidents in children. Indian Pediatr 1993;30:765-9.

7. Sharma AK, Sarin YK, Manocha S, et al. Pattern of childhood trauma. Indian perspective. Indian Pediatr 1993;30:57-60.

8. Fatmi Z, Hadden WC, Razzak JA, et al. Incidence, patterns and severity of reported unintentional injuries in Pakistan for persons five years and older: results of the National Health Survey of Pakistan 1990-94. BMC Public Health 2007;7:152.

9. Ministry of Home Affairs. Major Cause-wise Medically Certified Deaths by Age Group and Sex according to National List (Based upon Tenth Revision of ICD) in India. Government of India, 2004. http://www.indiastat.com/Health/16/MedicalC ertificationofCauseofDeath/48276/479869/data.aspx (accessed 27 Sep 2010).

10. Giashuddin SM, Rahman A, Rahman F, et al. Socioeconomic inequality in child injury in Bangladesh - implication for developing countries. Int J Equity Health 2009;8:7.

11. Rahman F, Rahman A, Linnan $M$, et al. The magnitude of child injuries in Bangladesh: a major child health problem. Inj Control Saf Promot 2004;11:153-7.

12. Kanchan T, Menezes RG, Monteiro FN. Fatal unintentional injuries among young children-a hospital based retrospective analysis. J Forensic Leg Med 2009;16:307-11.

13. Gupta SK, Peshin SS, Srivastava A, et al. A study of childhood poisoning at National Poisons Information Centre, All India Institute of Medical Sciences, New Delhi. J Occup Health 2003;45:191-6.

14. Iqbal A, Shirin T, Ahmed T, et al. Childhood mortality due to drowning in rura Matlab of Bangladesh: magnitude of the problem and proposed solutions. $J$ Health Popul Nutr 2007;25:370-6.

15. Singh S, Singhi S, Sood NK, et al. Changing pattern of childhood poisoning (19701989): experience of a large north Indian hospital. Indian Pediatr 1995;32:331-6.

16. Bose A, Konradsen F, John J, et al. Mortality rate and years of life lost from unintentional injury and suicide in South India. Trop Med Int Health 2006;11:1553-6

17. Abantanga FA, Mock CN. Childhood injuries in an urban area of Ghana a hospital-based study of 677 cases. Pediatr Surg Int 1998;13:515-18.

18. Thanh NX, Hang HM, Chuc NT, et al. Does poverty lead to non-fatal unintentional injuries in rural Vietnam? Int J Inj Contr Saf Promot 2005;12:31-7.

19. Cubbin C, Smith GS. Socioeconomic inequalities in injury: critical issues in design and analysis. Annu Rev Public Health 2002:23:349-75.

20. Dowswell T, Towner E. Social deprivation and the prevention of unintentional injury in childhood: a systematic review. Health Educ Res 2002;17:221-37.

21. Chibwana C, Mhango T, Molyneux EM. Childhood poisoning at the Queen Elizabeth Central Hospital, Blantyre, Malawi. East Afr Med J 2001;78:292-5.

22. Lang T, Thuo N, Akech S. Accidental paraffin poisoning in Kenyan children. Trop Med Int Health 2008;13:845-7.

23. Borse NN, Hyder AA, Streatfield PK, et al. Childhood drowning and traditional rescue measures: case study from Matlab, Bangladesh. Arch Dis Child 2011;96:675-80.

24. Chowdhury SM, Rahman A, Mashreky SR, et al. The Horizon of Unintentional Injuries among Children in Low-Income Setting: An Overview from Bangladesh Health and Injury Survey. J Environ Public Health 2009;2009:435403.

25. Shotar AM. Kerosene poisoning in childhood: a 6-year prospective study at the Princess Rahmat Teaching Hospital. Neuro Endocrinol Lett 2005;26:835-8.

26. Krug A, Ellis JB, Hay IT, et al. The impact of child-resistant containers on the incidence of paraffin (kerosene) ingestion in children. S Afr Med J 1994:84:730-4. 